\title{
Delivery of Hypoxia Inducible Heme Oxygenase-1 Gene Using Dexamethasone Conjugated Polyethylenimine for Protection of Cardiomyocytes under Hypoxia
}

\author{
Hyunjung Kim, Hyun Ah Kim, Joon Sig Choi, ${ }^{\dagger}$ and Minhyung Lee ${ }^{\star}$ \\ Department of Bioengineering, College of Engineering, Hanvang Lniversity, Seoul 133-791, Korea \\ E-mail: minhwingohanvang ac. $k$ ' \\ ${ }^{\dagger}$ Department of Biochemistry, College of Natural Science, Chungnam National Ciniversity, Daejeon 305-764, Korea \\ Received February 12, 2009. Accepted March 4, 2009
}

\begin{abstract}
Heme oxygenase- $1(\mathrm{HO}-\mathrm{l})$ is an anti-inflammatory and anti-apoptotic protein and has been applied to various gene therapy researches. However, constitutive expression of $\mathrm{HO}-\mathrm{l}$ may induce deleterious side effects. In this research, hypoxia inducible HO-l expression plasmid, $\mathrm{pEpo-SV-HO-1}$, was constructed with the ery thropoietin (epo) enhancer and simian virus $40(\mathrm{SV} 40)$ promoter to avoid these unwanted side effects. Dexamethasone conjugated polyethylenimine (PEI-Dexa) was used as a gene carrier. It was previously reported that dexamethasone protected cardiomy ocytes from apoptosis under hypoxia. In this research. PEI-Dexa reduced the caspase-3 level in hypoxic $\mathrm{H} 9 \mathrm{C} 2$ cardiomyocytes as a derivative of dexamethasone, suggesting that PEI-Dexa is an anti-apoptotic reagent as well as a gene carrier. pEpo-SV-HO-l was transfected to $\mathrm{H} 9 \mathrm{C} 2$ cardiomyocytes using PEI-Dexa and the cells were incubated under nomoxia or hypoxia. HO-l expression was induced in the $\mathrm{pEpo-SV}-\mathrm{HO}-1$ transfected cells under hypoxia. In addition, cell viability under hypoxia was higher in the $\mathrm{pEpo-SV-HO-I}$ transfected cells than the pEpo-SV-Luc transfected cells. Also, caspase-3 level was reduced in the pEpo-SV-HO-I transfected cells under hy poxia. In addition to the anti-apoptotic effect of PEI-Dexa, hypoxia inducible HO-l expression by pEpo-SVHO-l may be helptul to protect cardiomyocy tes under hypoxia. Therefore, $\mathrm{pEpo-SV-HO-1/PEI-Dexa} \mathrm{complex} \mathrm{may}$ be useful for ischemic heart disease gene therapy.
\end{abstract}

Key Words: Dexamethasone. Cardionyocytes. Heme oxygenase-1. Hypoxia. Polyethylenimine

\section{Introduction}

Heme oxygenase- 1 (HO-1) is an enzyme involved in heme degradation. ${ }^{1} \mathrm{HO}-\mathrm{I}$ is induced in response to various cellular stresses such as inflammation and hypoxia. ${ }^{3.3}$ HO-l has anti-inflammatory and anti-apoptotic effects and has been used as a therapeutic protein. ${ }^{+.5}$ It was reported that $\mathrm{HO}-\mathrm{l}$ was induced in the heart under ischemic condition and had a protective effect on cardiomyocytes. ${ }^{6}$ Also, it protected cells from the angiotensin II-induced apoptosis by inhibiting the MAP kinase cascade. ${ }^{1.8}$ Recently it was reported that $\mathrm{HO}-1$ was induced in acute lung injury and protected cells from the damage by reactive oxygen radical species. ${ }^{9-12}$ Due to this cytoprotective effect of $\mathrm{HO}-1$, gene therapy with $\mathrm{HO}-1$ gene has been suggested as a useful strategy for ischemic heart disease or stroke. Some gene therapy studies showed that HO-1 expression by gene delivery had cytoprotection effect in ischemic tissues. ${ }^{13.14}$ However. constitutive expression of HO-1 may have deleterious effect such as tumor growth. Also. it was previously reported that constitutive over expression of HO-1 may induce kernicterus and tissue hypoxia. which were caused by over-production of by-products of herne degradation. ${ }^{13.15}$ Therefore. HO-1 expression should be carefully modulated to avoid these side-effects. Previously. a tissue-specific promoter the my'osin light chain-2v (MLC-2v) promoter was employed to limit gene expression to cardiomy'ocy'tes. ${ }^{13.14}$ In combination with the MLC-2v promoter the oxygen dependent degradation domain (ODD) was applied to the $\mathrm{HO}-1$ expression vector to promote degradation of $\mathrm{HO}-1$ under normoxia. The ODD domain stabilized the HO-I protein under hypoxia.

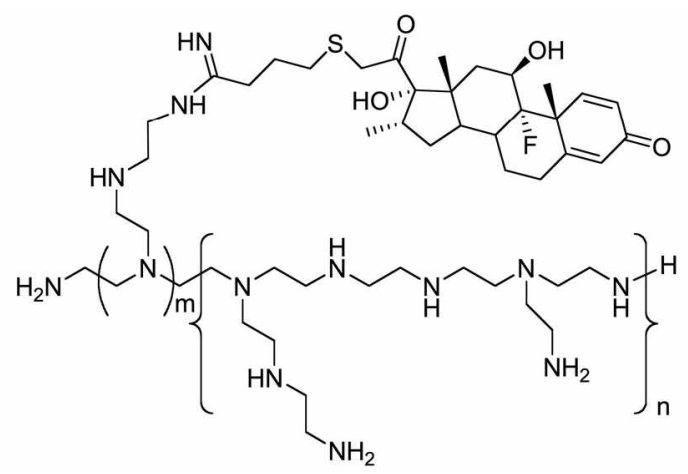

Figure 1. Structure of PEI-Dexa.

Dexamethasone is a potent glucocorticoid with antiinflammatory activity. Dexamethasone was conjugated to low molecular weight polyethylenimine (PEI2K. $2 \mathrm{kDa}$ ). ${ }^{16} \mathrm{High}$ molecular weight polyetlyylenimine (PEI25K. $25 \mathrm{kDa}$ ) has higher transfection efficiency than PEI2K. However. PEI25K is not clinically applicable, since it is highly toxic to cells. On the contrary. PEI2K is not toxic to cells. although its transfection efficiency was much lower than PEI25K. In our previous report, the transfection efficiency of PEI2K was improved by the conjugation of dexamethasone (Fig. 1). ${ }^{16}$ Dexamethasone binds to a glucocorticoid receptor after cellular entry: and the receptor/dexamethasone complex subsequently translocates it into the nucleus. ${ }^{17,18}$ Therefore. the nuclear trafficking of dexamethasone may facilitate the muclear entry of PEI-Dexa/DNA complexes. which in turn. increases the expression of the transfected gene. One of the important biological activities of dexamethasone is the cyto- 
protective effect of cardionyocytes from apoptosis. ${ }^{19}$ In the previous studies. it was shown that the treatment with dexamethasone reduced apoptosis of cardiomy ocytes under oxidative stress. $^{19 . \beth 1}$ Therefore, dexamethasone conjugated polymer may also have an anti-apoptotic effect in hypoxic cardiomyocytes as a derivative of dexamethasone. Indeed. PEI-Dexa had anti-apoptotic effect in cardiomyocytes in the presence of $\mathrm{H}_{2} \mathrm{O}_{2}{ }^{2}$ However. it was reported that dexamethasone might reduce the HO-l promoter activity. reducing the endogenous HO-I expression level. ${ }^{\lambda^{3}}$ This possible drawback of dexamethasone-conjugated polymer can be compensated by delivery of exogenous $\mathrm{HO}-\mathrm{I}$ gene. In this study. hypoxia inducible HO- 1 was constructed to avoid the deleterious side effects caused by non-specific expression. Previously our group developed various hỵpoxia regulatory expression sy stems for transcriptional, post-transcriptional, or post-translational re-

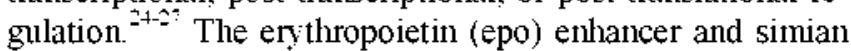
virus 40 (SV40) promoter system can induce gene transcription specifically under hypoxia. ${ }^{*}$ Therefore. a hypoxia specific transcriptional regulatory $\mathrm{HO}-1$ expression plasmid. pEpo-SV-HO-l was constructed with the epo enhancer and SV40 promoter system. pEpo-SV-HO-1 was transfected into H9C 2 cardiomyocytes and anti-apoptotic effect of PEI-Dexa and pEpo-SV-HO-I under hypoxia were evaluated. The results suggest that PEI-Dexa/hypoxia inducible HO-1 gene complex can protect cardiomyocytes under hypoxia and may be useful for ischemic heart disease gene therapy.

\section{Materials and Methods}

Synthesis of PEI-Dexa. PEI-Dexa was synthesized as previously described. ${ }^{16}$ Low molecular weight PEI (PEI2K, 2 $\mathrm{kDa}$ was dissolved in $1.8 \mathrm{~mL}$ anhydrous dimethyl sulfoxide (DMSO) with 2-fold molar excess Traut's reagent and dexamethasone-21-mesylate. To minimize the cross-linking side reaction. anhydrous DMSO was used and humidity was mitigated during the reaction. The reaction was allowed to proceed for 4 hrs at room temperature and was quenched by the addition of an excess amount of cold ethyl acetate. The precipitated product was solubilized in water and dialyzed for $\mathrm{I}$ day against pure water using a dialysis membrane (MWCO 1.000 ). The mixture was further freeze-dried. and a white product was obtained $(60 \%$. yield).

Preparation of Plasmid DNA. pEpo-SV-Luc was constructed previously. ${ }^{28}$ The human heme oxygenase-1 cDNA (Genebank accession number: NM002133) was cloned by RT-PCR using total RNA from 293 cells as a template. The sequences of the primers are as follows: forward primer. $5^{\circ}$-CCCA AGCTTATGGAGCGTCCGCAACCCG-3", backward primer. 5 -GCTCTAGAGCATTCACATGGCATAAAGC-3'. HinD III and XbaI sites were incorporated into the forward and backward primers. respectively, for cloning convenience (The enzyme sites are underlined). The amplified HO-I cDNA was inserted into pEpo-SV-Luc (pGL3-promoter, Promega, Madison. WI) at the place of the luciferase cDNA. resulting in the construction of pEpo-SV-HO-1. The construction of the plasmids was confirmed by restriction enzy me analysis and direct sequencing
Plasmid DNAs (pDNAs) were transformed in Escherichia Coli DH5 $\alpha$ and amplified in Terrific Broth media at $37{ }^{\circ} \mathrm{C}$ overnight at $220 \mathrm{rpm}$. The plasmid was purified using the Maxi plasmid purification kit (Qiagen, Valencia, CA).

Cell Culture and Transfection. $\mathrm{H} 9 \mathrm{C} 2$ rat cardiomyocytes were purchased from Korean Cell Line Bank (Seoul, Korea). The cells were maintained in DMEM supplemented with $10 \%$ FBS in a $5 \% \mathrm{CO}_{2}$ incubator. For the transfection assays. the cell was seeded at a density of $1 \times 10^{5}$ cells/well in 6-1well flatbottomed microassay plates (Falcon Co.. Becton Dickenson. Franklin Lakes, NJ) $2+$ lurs before the transfection. PEI2K/ pDNA and PEI-Dexa/plașinid complex was prepared at an $8 / 1$ weight ratio. based on the previous report. ${ }^{6}$ Transfection was performed as described in the previous reports. ${ }^{29-35}$ Before transfection. the medium was replaced with $2 \mathrm{~mL}$ of fresh DMEM with or without FBS. Then, the polymer/pDNA complexes were added to the cells. The amount of plasmid was fixed at $2 \mu \mathrm{g} / \mathrm{well}$. The cells were then incubated for 4 lus at $37^{\circ} \mathrm{C}$ in a $5 \% \mathrm{CO}_{2}$ incubator. After 4 hrs, the transfection mixtures were removed, and $2 \mathrm{~mL}$ of fresh DMEM medium containing FBS was added. The cells were incubated for an additional 44 hrs at $37^{\circ} \mathrm{C}$ under the hypoxia condition ( $1 \%$ $\left.\mathrm{O}_{2}\right)$ or normoxia condition $\left(5 \% \mathrm{CO}_{2}\right)$.

Enzyme-Linked Immunosoltent Assay (ELISA) of HO-1.

ELISA was performed using a human HO-1 ELISA Kit (Assay Designs. Ann Arbor. MI) to measure the human heme oxygenase- $\mathrm{I}$ in cell lysates. Briefly, the cells were harvested and lysated using extraction reagent (Assay Designs. Ann Arbor, MI). Fifty microliters of the samples were added to the designated wells. One hundred nucroliters of anti-human $\mathrm{HO}-\mathrm{l}$ rabbit polyclonal antibody was added to each well. and the plate was incubated at room temperature for 1 hour. After washing. $100 \mu \mathrm{L}$ of the horseradish peroxidase conjugated to anti-rabbit IgG was added into each well, and the plate was incubated at room temperature for $30 \mathrm{~min}$. After washing, 100 $\mu \mathrm{L}$ of the stabilized tetramethy lbenzidine substrate was added to each well, and the plate was incubated at roon temperature for $15 \mathrm{~min}$. After incubation. the stop solution was added to the wells. and the absorbance was measured at $450 \mathrm{~mm}$.

Apoptosis Assay. Apoptosis of the transfected cells was measured using Caspase-Glo 3/7 Assay reagent (Promega. Madison. WI). For transfection, the $\mathrm{H} 9 \mathrm{C} 2$ cells were seeded at a density of $5 \times 10^{3}$ cells/well in 96-well flat-bottomed nicroassay plates (Falcon Co., Becton Dickenson. Franklin Lakes, NJ) 24 hrs before the transfection. PEI2K/pDNA and PEI-Dexa/pDNA complexes were prepared at an $8 / 1$ weight ratio. Before transfection the medium was replaced with 200 $\mu \mathrm{L}$ of fresh medium without FBS. Then polymer/pDNA complexes were added to the cells. The amount of pDNA was fixed at a $0.2 \mu \mathrm{g} / \mathrm{well}$. The cells were then incubated for $+\mathrm{hrs}$ at $37^{\circ} \mathrm{C}$ in a $5 \% \mathrm{CO}_{2}$ incubator. After $4 \mathrm{hrs}$, the transfection nixtures were removed, and $100 \mu \mathrm{L}$ of fresh DMEM medium containing FBS was added. The cells were incubated for an additional +4 lurs at $37^{\circ} \mathrm{C}$ under the nonmoxia ( $20 \%$ oxygen) or hyp poxia condition ( $1 \%$ oxygen). After incubation. $50 \mu \mathrm{L}$ of Caspase-Glo reagent was added to each well. and samples are incubated at room temperature for $1 \mathrm{hr}$. The luminescence of each sample was measured in terms of relative light units 
(RLU). using a 96-well plate luminometer (Berthold Detection System GmbH. Pforzheim. Germany).

Cell Viability Assay. The evaluation of cell viability was performed by the MTT assay. ${ }^{36-39} \mathrm{H} 9 \mathrm{C} 2$ cells were seeded at a density of $1.3 \times 10^{4}$ per well in $2+$-well plates and incubated for 24 hrs before transfection. PEI2K/pDNA and PEI-Dexa/ pDNA complexes were prepared at an $8 / 1$ weight ratio. The amount of pDNA was fixed at $0.25 \mu \mathrm{g} / \mathrm{well}$. The medium was replaced with fresh DMEM medium without FBS before transfection and polymer/pDNA complex was added to the cells. After incubation at $37^{\circ} \mathrm{C}$ for + hrs, the transfection mixture was replaced with $500 \mu \mathrm{L}$ of fresh DMEM medium supplemented with $10 \%$ FBS, and the cells were incubated for The cells were incubated for an additional +4 hrs at $37{ }^{\circ} \mathrm{C}$ under the hypoxia condition $\left(1 \% \mathrm{O}_{2}\right)$ or normoxia condition $\left(5 \% \mathrm{CO}_{2}\right)$. MTT solution in PBS was added. The cells were incubated for an additional + hrs at $37^{\circ} \mathrm{C}$. at which point. MTT-containing medium was aspirated off, and $750 \mu \mathrm{L}$ of DMSO was added to dissolve the formazan cry stal formed by live cells. Absorbance was measured at 570 nun. The cell viability (\%) was calculated according to the following equation:

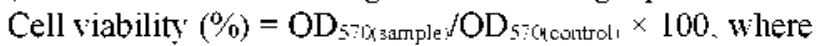
the $\mathrm{OD}_{5 \text { ix }}$ sanyly represents the measurement from the well treated with poly mer/plasmid DNA complex and the $\mathrm{OD}_{5: \text { incontrol }}$ represents the measurements from the wells treated with $5 \%$ glucose.

Statistical Analysis. Results were reported as mean \pm standard deviation. The comparison of luciferase activity or HO-l concentration was made by Student 's $t$-test. A $P$ value less than 0.05 was considered statistically significant.

\section{Results}

Anti-apoptotic effect of PEI-Dexa. To evaluate cytoprotective effect of PEI-Dexa, PEI-Dexa/pEpo-SV-Luc complex was transfected into $\mathrm{H} 9 \mathrm{C} 2$ cells. After transfection. the cells were incubated under hypoxic condition. The apoptotic level of the cells was measured by caspase-3 assay. The results showed that PEI $2 \mathrm{~K} / \mathrm{pEpo-SV}$-Luc complex did not have significant effect on the caspase-3 activity compared with the control (Fig. 2). However. capase-3 activity in the cells transfected with PEI-Dexa/pEpo-SV-Luc was lower than that in the cells transfected with PEI2K/pEpo-SV-Luc complex (Fig. 2). These results suggest that the dexamethasone conjugated to PEI2K had anti-apoptotic effect.

Construction of pEpo-SV-HO-1 and hypoxia inducible HO-1 expression. For hypoxia inducible gene expression, transcriptional regulation plasmid of the $\mathrm{HO}-1$ gene was constructed with the epo enhancer and SV40 promoter (Fig. 3). The HO-1 cDNA was inserted at the place of the luciferase gene in pEpo-SV-Luc. The construction of the plasmid was confirmed by DNA sequencing.

pEpo-SV-HO-1 was transfected into $\mathrm{H} 9 \mathrm{C} 2$ cells using PEI-Dexa as a gene carrier. pEpo-SV-Luc was also transfected as a control. After the transfection. the cells were incubated under normoxia or hypoxia. After $2+$ hrs of transfection. the cell extracts were subjected to ELISA. As a result. the pEpoSV-Luc transfected cells showed basal level of endogenous

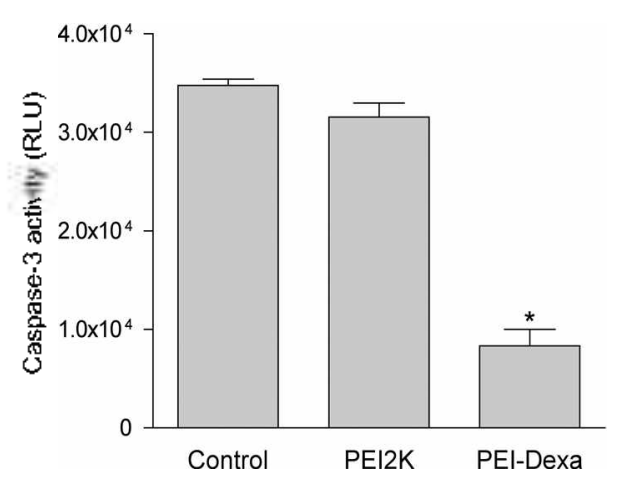

Figure 2. Caspase-3 activity after transfection of PEI-Dexa/pEpoSV-Luc complex. PEI2K/pEpo-SV-Luc or PEI-Dexa/pEpo-SV-Luc complexes were prepared and transfected to $\mathrm{H} 9 \mathrm{C} 2$ cells. The cells were incubated under hypoxia for 44 hrs. Apoptosis level was measured by Caspase-3 activity. The data is expressed as the mean values ( \pm standard deviation) of quadruplicated experiments. ${ }^{*} \mathrm{P}<$ 0.05 as compared with PEI-Dexa/pSV-Luc.

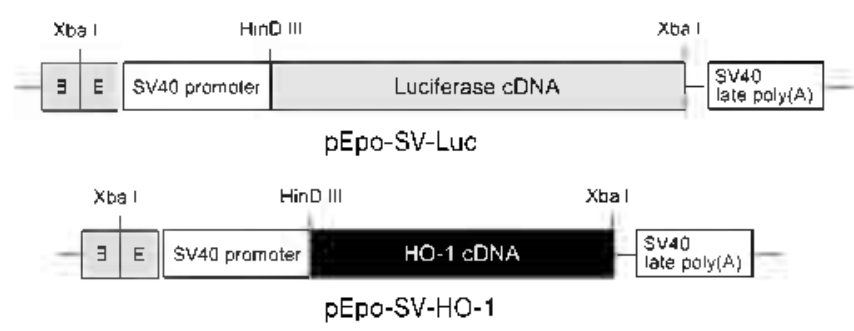

Figure 3. Structures of pEpo-SV-Luc and pEpo-SV-HO-1 . E indicates the erythropoietin enhancer.

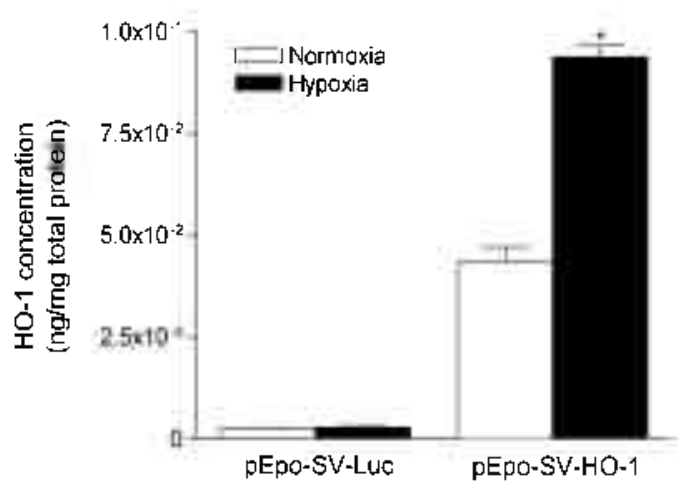

Figure 4. $\mathrm{HO}-1$ expression in $\mathrm{H} 9 \mathrm{C} 2$ cells under nonmal or hypoxic conditions. $\mathrm{pEpo-SV-Luc}$ and $\mathrm{pEpo-SV-HO-1}$ were transtected into $\mathrm{H} 9 \mathrm{C} 2$ cells using PEI-Dexa as a gene carrier. The cells were incubated under normal or hypoxic conditions for 44 hrs. $\mathrm{HO}-1$ expression levels were measured by HO-l ELISA. The data are expressed as the mean values ( \pm standard deviation) of quadruplicated experiments. ${ }^{*} \mathrm{P}<0.01$ as compared with $\mathrm{pEpo-SV}$-HO-I under normoxia and pEpo-SV-Luc.

HO-l protein (Fig. 4). However. the transfection of pEpoSV-HO-1 elevated HO-1 level in the cells (Fig. 4). Especially, the pEpo-SV-HO-l transfected cells under hypoxia showed approximately twice higher $\mathrm{HO}-1$ expression than the cells under normoxia. suggesting that $\mathrm{HO}-\mathrm{l}$ expression under 


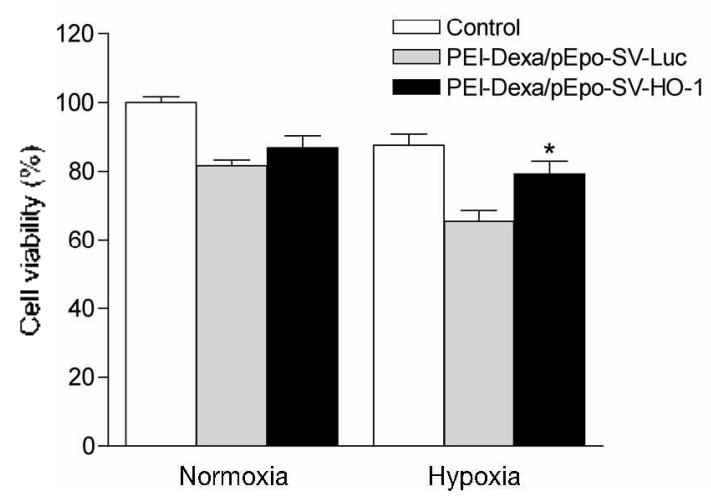

Figure 5. Viabilitv of hvpoxic H9C2 cells after transtection of PEIDexa/pEpo-SV-Luc or PEI/Dexa/pEpo-SV-HO-1 complex. pEpoSV-Luc and pEpo-SV-HO-1 were transfected into H9C2 cells using PEI-Dexa as a gene carrier. The cells were incubated under nonmal or hypoxic conditions for 44 hrs. Cell viability was determined by MTT assay. The data is expressed as the mean values ( \pm standard deviation) of quadruplicated esperiments. ${ }^{*} \mathrm{P}<0.05$ as compared with PEIDexa/pEpo-SV-Luc under hypoxia.

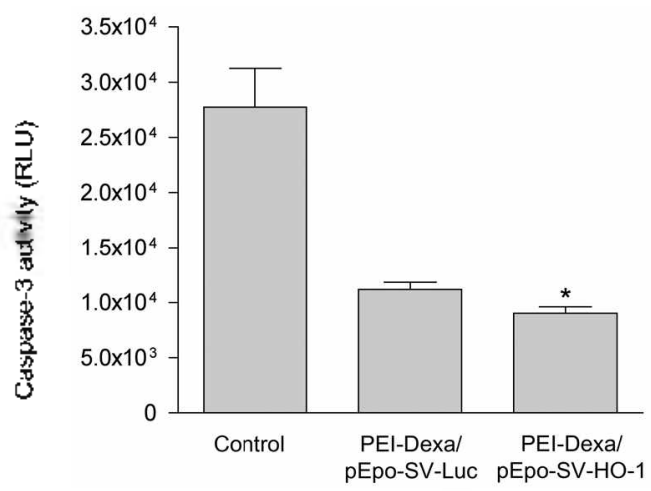

Figure 6. Caspase-3 activity after transfection of PEI-Dexa/pEpoSV-HO-I complex. PEI-Dexa/pEpo-SV-Luc or PEI-Dexa/pEpo-SV$\mathrm{HO}-\mathrm{I}$ complexes were prepared and transtected to $\mathrm{H} 9 \mathrm{C} 2$ cells. The cells were incubated under hy posia for $44 \mathrm{hrs}$. Apoptosis level was measured by Caspase- 3 activity. The data is expressed as the mean values ( \pm standard deviation) of quadruplicated experiments. ${ }^{*} \mathrm{P}<$ 0.05 as compared with PEI-Dexa/pEpo-SV-Luc

hypoxia was transcriptionally induced by the epo enhancer.

Effect of hypoxia inducible HO-1 expression. Under hypoxia. $\mathrm{H} 9 \mathrm{C} 2$ cells are prone to apoptosis. The cell viability under hypoxia was evaluated by MTT assay. The cells were transfected with PEI-Dexa/pEpo-SV-Luc or PEI-Dexa/pEpoSV-HO-1. The control cells were treated with only PBS. Due to the toxicity of polymeric carrier, PEI-Dexa, the cell viability of the PEI-Dexa/pEpo-SV-Luc treated cells was lower than that of the control (Fig. 5). Under normoxia, the cells treated with PEI-Dexa/pEpo-SV-HO-I complex showed a slightly lugher vlability than the cells treated with PEI-Dexa/pEpoSV-Luc. which was not statically significant (Fig. 5). However. the viability of the cells transfected with PEI-Dexa/pEpoSV-HO-1 complex was significantly higher than that of the cells transfected with PEI-Dexa/pEpo-SV-Luc complex.

Apoptosis level of the cells were measured by caspase-3 assay. Fig. 6 showed that the cells transfected with PEI-Dexa/
pEpo-SV-HO-1 complex had lower capase-3 level than the cells transfected with PEI-Dexa/pEpo-SV-Luc (Fig. 6). This suggests that apoptosis level was lower in the pEpo-SV-HO-l transfected cells, conpared with the pEpo-SV-Luc transfected cells.

\section{Discussion}

In this study, we evaluated the effect of hypoxia-inducible HO-l gene delivery using PEI-Dexa. In combination with PEI-Dexa. HO-l gene may have șinergistic effect with PEI-Dexa for protection of cardionyocytes under hypoxia. In this study. the hypoxia inducible $\mathrm{HO}-\mathrm{I}$ plasmid. pEpo-SV$\mathrm{HO}-1$ showed lugher $\mathrm{HO}-1$ expression in hypoxic $\mathrm{H} 9 \mathrm{C} 2$ cells (F1g. 4) and protected the cells from apoptosis (Figs. 5 and 6).

Hypoxia inducible gene expression can be achueved at transcriptional. translational, or post-translational step. For translational regulation. hypoxia specific untranslated region (UTR) such as the epo 3'-UTR can be integrated into the therapeutic gene. ${ }^{26}$ The epo RNA binding protein (ERBP) binds to the epo $3^{\circ}$-UTR and stabilizes the epo $3^{\prime}$-UTR linked mRNA under hypoxia. For post-translational regulation, the oxygen dependent degradation (ODD) domain can be integrated into therapeutic gene to produce a fusion protein. ${ }^{2 ?}$ Under normoxia. the fussion protein with the ODD domain is midly degraded via proteasome pathway, while it is stabilized under hypoxia. In this research. the epo enhancer increased HO-I expression under hypoxia effectively (Fig. 4). The transcriptional, translational and post-translational regulatory mechanisms are independent of each other. Therefore. the combination with transcnptional, translational and posttranslational regulations will further improve the HO-l expression specificity and may be more useful for safe gene therapy.

Dexamethasone has an anti-inflammatory or ant1-apoptotic effect in ischenuc myocardium. ${ }^{\text {[9.2] }}$ Recently, it was also reported that ischemic brain could be protected by the adminstration of dexamethasone. ${ }^{4(1+1)}$ Dexamethasone was conjugated to PEI2K to apply the anti-apoptotic effect of dexamethasone to 1schemic heart disease therapy. ${ }^{16}$ The conjugation of dexamethasone increased the transfection efficiency of PEI2K and PEI-Dexa has higher transfection efficiency than PEI2K. The efficiency of PEI-Dexa was comparable to that of PEI25K. one of the most efficient poly meric camers. Also, PEI-Dexa was less toxic than PEI25K. These characteristics of PEI-Dexa suggest that PEI-Dexa is a useful gene carrier. Furthermore, dexamethasone segment of PEIDexa retains anti-apoptotic effect. In the previous report, we showed that PEI-Dexa protected cardiomyocytes in the presence of $\mathrm{H}_{2} \mathrm{O}_{2}{ }^{2-2}$ This anti-apoptotic effect of PEI-Dexa was confinmed in cardiomỵocytes under hỵpoxia (Fig. 2). Therefore. PEI-Dexa is an efficient gene camer with antiapoptotic effect.

Previously, it was suggested that dexamethasone might reduce the $\mathrm{HO}-1$ promoter activity, which resulted in the reduced level of endogenous $\mathrm{HO}-1$. "3 This may hamper the antl-apoptotic effect dexamethasone in ischemic myocardium. The disadvantage of dexamethasone. reducing $\mathrm{HO}-1$ level, may be compensated by the delivery of the HO-l gene. As 
shown in Fig. 2 and 6. capase-3 level was reduced by PEIDexa and further decreased by $\mathrm{HO}-\mathrm{I}$ gene. The cell viability under hypoxia was improved in the cells transfected with PEI-Dexa/pEpo-SV-HO-1 complex (Fig. 5).

As in Fig. 2. PEI-Dexa reduced caspase-3 level significantly compared with the control. However, the viability of the cells treated with PEI-Dexa was lower than the control in Fig. 5. These suggest that the cell death in the control was caused by necrosis as well as apoptosis. Although PEI-Dexa was less toxic than PEI25K it still induces a certain level of toxicity to cells. ${ }^{16,2}$ Even though PEI-Dexa reduced apoptosis level, the necrosis level might be higher in the PEI-Dexa treated cells than the control. The necrosis of the cells may be due to cationic charge of the polymer. This necrosis may be limited to early phase of transfection. It was previously suggested that cytotoxicity of PEI has two phases. immediate and delayed toxicities. ${ }^{4-2}$ Immediate toxicity is mainly due to free PEI. Free PEI has higher charge density than PEI/DNA complex and aggregates at the surface of plasma membrane. The aggregation causes necrosis by the rupture of the membrane. At the delayed phase. toxicity is mainly due to the internalized PEI/DNA complex. After release of DNA. PEI binds to negatively charged molecules in the cells. This interaction may interrupt with normal cellular process and induce apoptosis. In the present study. MTT assay was performed at the early phase after 24 hrs of incubation. Although PEI-Dexa has anti-apoptotic effect. it may not be able to prevent necrosis caused by the immediate toxicity of free PEI-Dexa. In the previous study, we showed that PEI25K/DNA complex had high apoptosis level at the delayed phase, compared with free PEI25K. ${ }^{43}$ We suggested that loss of gene expression in the transfected cells might be due to apoptosis of the transfected cells at the delayed phase. ${ }^{43}$ Since PEI-Dexa may protect the cells from apoptosis at the delayed phase and reduce the loss of transfected cells, the gene expression may be more persistent in the cells transfected with PEI-Dexa than the cells transfected with PEI $55 \mathrm{~K}$. It would be interesting to whether PEI-Dexa can increase gene expression duration compared with PEI25K.

In conclusion. PEI-Dexa reduced the caspase- 3 level in the H9C2 cells under hypoxia. The anti-apoptotic effect was further increased by delivery of hypoxia inducible $\mathrm{HO}-1$ plasmid. pEpo-SV-HO-1. using PEI-Dexa. Therefore, PEI-Dexa/ pEpo-SV-HO-1 complex may be useful for protection of cardiomyocy tes under hy poxia and gene therapy of ischemic diseases.

Acknowledgments. This work was supported by the research fund by Hanyang University (HY-2007-I).

\section{References}

1. Tongers, T.; Fiedler, B; Konig, D: Kempf, T: Klein, G.: Heineke, $\mathrm{T}$. Kraft, T.: Gambaryan, S.: Lolunan, S. M.: Drexler, H.; Wollert, K. C. Candiovasc. Res. 2004, 3, 545.

2. Kacimi, R.: Chentoufi, J.; Honbo, N.: Long, C. S : Karliner, J. S. Candiovasc. Res. $2000,1,139$.

3. Takahashi, T:- Shimizu, H.; Morimatsu, H.; Inoue, K: Akagi, R.; Morita, K.: Sassa, S. Mini Rev Med. Chem 2007, 7, 745.

4. Idriss, N. K :Blann, A. D : Lip, G. Y. J. Am. Coll Carliol. 2008, 12,971

5. Abraham, N. G.: Kappas, A. Phamacol. Rev 2008, 1, 79.
6. Yet, S. F.: Tian, R.: Layne, M. D.: Wang. Z. Y.: Maemura, K.; Solovyeva, M.; Ith, B.; Melo, L. G.; Zhang, L.; Ingwall, T. S.; Dzau, V. J.: Lee, M. E.; Perrella, M. A. Cik Res. 2001, 2, 168.

7. Hu, C. M.; Chen, Y. H.; Chiang, M. T.: Chan, L. Y. Circulation 2004, 3, 309 .

8. Foo, R. S.: Siow, R. C.: Brown, M. J.: Bennett, M. R. J. Cell. Physiol. 2006, 1, 1

9. Jin, Y.: Choi, A. M. Proc Am Thorac Soc 2005, 3, 232.

10. Ryter, S. W.: Kim, H. P.; Nakahira, K.; Zuckerbraun, B. S.; Morse, D.: Choi, A. M. Antioxid. Redor. Signal 2007, 12, 2157.

11. Pang, Q. F.; Zhou, Q. M.; Zeng, S.; Dou, L. D.; Ji, Y.; Zeng, Y. M. Chin . Hed J. (Engl) 2008, 17, 1688.

12. Chen, C.; Wang, Y. L.; Wang, C. Y.; Zhang, Z. Z. Chin. J. Tranmatol $2008,2,78$.

13. Tang, Y. L.; Tang, Y.; Zhang, Y. C.; Qian, K.; Shen, L.; Phillips, M. I. Hupentension 2004, 4,746

14. Tang, Y. L.; Qian, K, Zhang, Y. C.; Shen, L.; Phillips, M. I. $J$. Cardiovasc. Phamacol Ther $\mathbf{2 0 0 5}, 4251$

15. Platt, .T. L.; Nath, K. A. Nat. Mfed. $1998,12,1364$

16. Bae. Y. M.: Choi. H.: Lee, S.: Kang. S. H.: Nam. K.: Kim. Y. T: Park, J. S.; Lee, M.; Choi, J. S. Bioconjug. Chem 2007, 6, 2029.

17. Adcock. I. M.: Caramori. G. Immmol Cell Biol 2001 i. 376.

18. Shahin, V:; Albemann, L.; Schillers, H.; Kastrup, L.; Schafer, C.: Ludwig, Y.: Stock, C.; Oberleithner, H. J. Cell Physiol 2005, 2,591

19. Chen, Q. M.: Alexander, D.; Sun, H.; Xie, L.: Lin, Y.; Tenand, T.; Morrisst, S.: Purdom, S. Mol Phamacol 2005, 6. 1861.

20. Sun, L.; Chang, J.; Kirchlhoff, S. R.; Knowlton, A. A. Am. J. Phusiol Heant Cinc. Phsiol 2000. + H1091.

21. Reeve, J. L.; Szegezdi, E.; Logue, S. E.; Chonghaile, T. N.; OBrien, T.; Ritter, T.; Samali, A.J. Cell Hol. Med 2007, $3,509$.

22. Kim, $\mathrm{H} ; \mathrm{Kim}, \mathrm{H}$. A $;$ Bae, Y. M.; Choi, J. S.; Lee, M. J. Gene Med. 2009, Published online, DOI: 10 . 1002/jgm. 1320 .

23. Deramaudt, T. B.; da Silva, J. L.; Remy, P.; Kappas, A.; Abraham, N. G. Proc. Soc. Exp. Biol. Med $1999,2,185$

24. Lee, J. W.; Bae, S. H.; Jeong, J. W.; Kim, S. H.; Kim, K. W. Exp. Mol. Med 2004, 1,1 .

25. Lee, M.; Bikram, M; Oh, S.; Bull, D. A.; Kim, S. W. Phomt. Res. $2004,5.736$.

26. Lee, M.; Choi, D.; Choi, M. T.; Teong, T. H.; Kim, W. T.; Oh, S.; Kim. Y. H.: Bull. D. A.: Kim. S. W. J. Control Release 2006, 1 , 113

27. Kim, H. A.; Kim, K; Kim, S. W: Lee, M. J. Control. Release $2007,3,218$

28. Lee, M.; Rentz, J.; Bikram, M.; Han, S.; Bull, D. A.; Kim, S. W. Gene Ther: 2003, 18, 1535 .

29. Choi, J. S.; Lee, E. J.; Choi, Y. H.: Jeong, Y. J.; Park, J. S. Bioconing. Chem 1999, 1,62

30. Choi, Y. H.: Liu, F.; Choi, T. S.; Kim, S. W.; Park, T. S. Hum. Gene Then 1999, 16, 2657.

31. Choi, I. S.; Too, D. K.; Kim, C. H.; Kim, K.; Park, J. S. J. Am. Chem Soc. 2000, 474

32. Lee, I. H.; Lim, Y. B.; Choi, I. S.: Lee, Y.; Kim, T. I.: Kim, H. I:; Yoon, J. K.: Kim, K.: Park J. S. Bioconjug. Chem. 2003, 6, 1214.

33. Kim, T. I.: Seo, H. J.: Choi, J. S.; Jang, H. S.; Baek, J. U.: Kim, K.: Park, T. S. Biontacromolecules 2004, 6, 2487.

34. Choi, J. S.; Nam, K.: Park, J. Y.; Kim, J. B.; Lee, J. K.: Park, I. S. J. Control Release $2004,3,445$.

35. Kim, T. I.; Seo, H. J.: Choi, J. S.; Yoon, J. K.: Baek, I. U.: Kim, K.; Park, T. S. Bioconjug. Chemt 2005, $5,1140$.

36. Kim, T. I.: Baek, I. U.: Yoon, I. K.: Choi, I. S.; Kim, K.: Park, I. S. Bioconing. Chem. 2007, 2, 309.

37. Kim, H. J.: Kwon, M. S.; Choi, J. S.: Kim. B. H.: Yoon, I. K.; Kim, K, Park, T. S. Bioong. Med. Chem. 2007, f, 1708.

38. Nam, H. Y.; Hahn, H. I.; Nam, K.; Choi, W. H.: Jeong. Y.: Kim, D. E. Park, T. S. Int. J. Pham. 2008, I-2, 199.

39. Nam, H. Y: Nam, K.: Hahn, H. J.: Kim, B. H.; Lim, H. J.: Kim, H. J. Choi, T. S.; Park, J. S. Biomaterials 2009, t.665.

40. Chang, C. N.: Yang, T. T.: Lee, T. H.; Cheng, W. C.: Hsu, Y. H.; Wu, J. H. $J$. Clin Netrosci. $2005,6,680$.

41. Malaeb, S. N.: Sadowská, G. B.: Stonestreet, B. S. Brain Res. 2007, 1160,11 .

42. Godbey. W. T.: Wul, K. K.: Mikos, A. G. Biomaterials 2001, 5. 471.

43. Lee, M. Bull Konem Chem. Soc 2007, 1,95. 